\section{Role of biochemical \\ parameters in the differential diagnosis of viable pregnancy, anembryonic pregnancy and intrauterine fetal exitus in cases of first trimester threatened abortion}

Birinci trimester düşük tehdidi olan hastalarda anembriyonik gebelik, intrauterin eksitus ve sağlıklı gebeliğin ayırıcı tanısinda biyokimyasal parametrelerin yeri

\author{
Ozan Özolcay ${ }^{1}$ \\ Bulat Aytek Şık ${ }^{2}$
}

\begin{abstract}
It is aimed to establish criteria about the prognosis and life potential of pregnancy by using ultrasonographic imaging techniques and hormonal parameters to evaluate embryonic life potantial in threatened miscarriage patients. Our study consists of 45 pregnant patients who were admitted for vaginal bleeding during pregnancy and were diagnosed as a threatened miscarriage. The study group consisted of pregnant women diagnosed with threat of miscarriage pregnancy week is lower than 20 weeks according to their last menstrual period.-Estradiol, Progestrone, $\beta$ hCG hormone level are measured from patients, the same day after the ultrasound examination. The group whose pregnancy resulted with live birth and the group whose pregnancy ended with spontaneous abortion were statistically compared according to their hormonal parameters; it was found to be
\end{abstract}

Özet

Düşük tehdidi olan hastalarda embriyonik yaşamın devamını değerlendirmek için ultrasonografik görüntüleme teknikleri ve hormonal belirteçleri kullanarak gebeliğin prognozu ve yaşam potansiyeli hakkında kriterler oluşturmak amaçlanmıştır. Çalışmamız, gebelikte vajinal kanama nedeniyle başvuran ve düşük tehdidi tanısı alan 45 gebe hastadan oluşmaktadır. Herhangi bir sistemik hastalığ1 bulunmayan ek bir jinekolojik patolojisi olmayan ve son adet tarihinden kesin olarak emin olan hastalar çalışma gruplarına dahil edildi. Çalışma grubu son adet tarihine göre 20 hafta ve daha küçük gestasyonel haftadaki düşük tehdidi tanıs1 alan gebelerden oluştu. Hastalardan Estradiol, Progestrone, $\beta$-hCG ölçümleri yapıldı. Gebeliği canlı doğum ile sonuçlanan grup ile gebeliği spontan abortusla sonlanan grubun $\beta$-hCG, $\mathrm{P}_{4}, \mathrm{E}_{2}$ degerleri

1 Op. Dr., Kadın Hastalıkları ve Doğum Bölümü, Taksim Eğitim ve Araştırma Hastanesi, ozan.ozolcay@gmail.com (iD) Orcid ID: 0000-0002-9416-6153

2 Op. Dr. Kadın Hastalıkları Doğum ve Tüp Bebek Bölümü, Şişli Kolan İnternational Hospital, bulataytek@gmail.com 
Özolcay, O., \& Șık, B. A. (2021). Birinci trimester düşük tehdidi olan hastalarda anembriyonik gebelik, intrauterin eksitus ve sağlıklı gebeliğin ayırıcı tanısında biyokimyasal parametrelerin yeri. Journal of Human Sciences, 18(3), 342-348. doi:10.14687/jhs.v18i3.6019

significantly lower in the group that resulted in live birth $(\mathrm{p}<0.01)$. Sensitivity, specificity, negative and positive predictive values of $\beta$ hCG, E2, P4 levels were found to be significant in patients with threatened miscarriage. Increase both time loss and correct diagnosis rate, after vaginal speculum examination the first choice in patients with abortus imminens is to request a transvaginal ultrasonographic examination and then assesment of hormonal parameters $(\beta$ hCG, progesterone, estradiol) if necessary.

Keywords: First trimester; Abortus imminens; Transvaginal ultrasonography; Estradiol; Progesterone; $\beta$-hCG.

(Extended English summary is at the end of this document) istatiksel olarak karşılaștırıldığında; canlı doğum ile sonuçlanan grupta anlamlı olarak düşük bulunmuştur $(p<0.01)$. Abortus imminensli hastalarda $\beta$-hCG, $\mathrm{E}_{2}, \mathrm{P}_{4}$ düzeylerinin sensivite spesifite, negatif ve pozitif prediktif değerleri anlamlı çıkmıştır. Abortus imminensli hastalarda vaginal muayene sonrası yapılacak ilk iş hem vakit kaybını hem de doğru tanı oranını arttırmak için ilk olarak transvajinal ultrasonografik inceleme ve ardindan gerekirse hormonal parametreleri ( $\beta$-hCG, progesteron, estradiol) istemek doğru olacaktır.

Anahtar Kelimeler: Birinci trimester; Abortus imminens; Transvajinal ultrasonografi; Estradiol; Progesteron; $\beta$-hCG.

\section{Giriş}

Düşük tehdidi klinik olarak saptanmış gebeliklerin \%25 gibi oldukça büyük bir kısmında görülebilen bir durumdur (Hertz 1984; Canavagh \& Comas 1982; Fantel \& Shepard 1981). Gebeliğin devamını sağlamak için uygulanan çeşitli tedavilere rağmen, bu gebeliklerin yaklaşık yarısı düşükle sonuçlanmaktadır (Ansan 1989; Filly 1988; Scott 1986). Bu hastalarda, embriyonun genellikle ilk kanama anında kalp atışları durmuştur veya uzun bir zamandan beri kalp atışları durmuşta olabilir. Bu nedenle kalp atı̧ları durmuş gebeliklerde abortusu engelleyecek ilaçların kullanılması etkisizdir, süreci uzatır ve koryonik doku hala aktif kalıp gebelik testlerinin pozitif ç1kmasina sebep olur (Ansan 1989; Scott 1986; Glass et al 1989).

Erken sağlıklı gebelik, anembriyonik gebelik ve intrauterin fetal/embriyonal eksitus olgularının ayırıcı tanısı ebeveynlerde bu sonuçlara neden olabilecek genetik faktörlerin araştırılmasında uyarıcı olabileceği gibi assiste reprodüktif teknolojilerin başarısının ve embriyo kalitesinin değerlendirilmesinde önemini korumaktadır (Homan et al. 2000; Hsu et al. 1998). Erken gebelik kaybının nedenlerini belirlemeye yönelik önemli araştırma girişimlerine rağmen hala tam olarak kesin sonuca ulaşılamamıştır. Kesin düşükle sonuçlanacak gebelikleri öngörmedeki başarı sınırlıdır. Erken gebelik kaybının öngörülmesi için fetal, plasental ve over kökenli hormonların, proteinlerin ölçümü, biyofiziksel testler ve ultrason muayenesinin spesifitesi ve sensitivitesi için çeşitli gruplar bir takım çalışmalar yapmıştır (Stabile et al. 1989; Westergaard et al. 1985; Salem et al. 1984).

Yardımla üreme tedavileri, yumurtlama ve gebe kalma zamanlamasının doğru izlenmesi ile gebe kalması muhtemel kadınların yakın ve dikkatli incelenmesine olanak vermis, gebe kalma döngüsü ve erken hamilelik sırasında meydana gelen olaylara odaklanmıştır. Daha önceki çalışmalar, gebelik sonucunun öngörülmesinde hormonal izleme potansiyelini göstermiştir (Yovkh 1986; Yovich et al. 1986).

Bu çalışmada düşük tehdidi semptomları olan hastalarda embriyonik yaşamı değerlendirmek için ultrasonografik görüntüleme teknikleri ve hormonal belirteç olarak da serum $\beta$-hCG, Estradiol, Progesteron seviyesi kullanılarak gebeliğin prognozu ve yaşam potansiyeli hakkında kriterler oluşturmak amaçlanmıştır. 
Özolcay, O., \& Şık, B. A. (2021). Birinci trimester düşük tehdidi olan hastalarda anembriyonik gebelik, intrauterin eksitus ve sağlıklı gebeliğin ayırıcı tanısında biyokimyasal parametrelerin yeri. Journal of Human Sciences, 18(3), 342-348. doi:10.14687/jhs.v18i3.6019

\section{Materyal ve Metod}

Çalışmamız, İstanbul Taksim Eğitim ve Araştırma Hastanesi Gebe Polikiniğine gebelikte vajinal kanama nedeniyle başvuran ve düşük tehdidi tanısı alan 45 gebe hastadan oluşmaktadır. Çalışma; Hastane eğitim planlama ve etik kurulun onayını takiben, aynı hastanenin Kadın Hastalıkları ve Doğum servisinde yürütülmüştür. Herhangi bir sistemik hastalığ1 bulunmayan ek bir jinekolojik patolojisi olmayan ve son adet tarihinden kesin olarak emin olan hastalar çalışma gruplarına dahil edildi. Vajinal muayene sonrası kanamanın bir servikal polip, erozyon veya eversiyondan kaynaklandığ1 kesinleşen gebeler, çoğul gebelikler, ektopik ve kimyasal gebelik tanıs1 alanlar çalışma dışında bırakıldılar. Çalışma grubu son adet tarihine göre 20 hafta ve daha küçük gestasyonel haftadaki düşük tehdidi tanısı alan gebelerden oluştu.

Çalışmaya dahil edilen tüm hastaların antekübital venlerinden $10 \mathrm{cc}$ kan alındı ve analiz edildi. Toplanan kan örneklerinin hepsinden ayn zamanda Estradiol (E2), Progestrone (P4), $\beta$ hCG ölçümleri yapıldı. Estradiol ve progesteron ölçümleri solid faz radioimmunoassay tekniği ile çalışan Coast A-Count Estradiol ve Progesteron kitleri ile yapıldı. $\beta$-hCG, ölçümleri ise sandwich radioimmunoassay tekniğine dayalı kitler olan IRMA-mat $\beta$-hCG, ile yapıldı.

Hastaların önce detaylı sistemik, jinekolojik ve obstetrik anamnezleri alındı ve Shimadzu marka SDU-350A model real time lineer konveks problu ultrasonografi cihazi ve EUP-V12 model $5 \mathrm{mHz}$ lik vajinal prob kullanılarak transvajinal sonografik pelvis incelemeleri yapıldı.

Ultrasonografik incelemede ana amaç fetal kalp hareketlerini saptamaktı. Embriyonun görülemediği erken gebeliklerde, gebelik kesesinin boyutunu 3 kadranda ölçüp ortalamasını almak suretiyle ortalama gebelik kesesi çapı (OGKÇ) bulundu. Fetal kalp hareketlerinin (FKH) saptanamadığı OGKÇ’nin 25 mm'den büyük olduğu gebelikler anembriyonik gebelik olarak kabul edildi ve terapotik küretaj uyguland. FKH'nin saptanamadığ 1 OGKÇ' nin $25 \mathrm{~mm}$ 'den küçük veya CRL 'nin $10 \mathrm{~mm}$ den küçük olduğu hastalarda bu incelemeye ek olarak Radioimmunoassay yöntemiyle $\beta$-hCG, progesteron, estradiol seviyesi ölçülmek üzere kan örneği alınıp bir hafta sonra kontrole çağrılmıştır. Fetus görülebiliyorsa CRL ve BPD ölçülmüş ve fetal kalp atım hareketlerine bakılmıştır. FKH saptanamayan 10 mm'den büyük embriyolar missed abortus olarak kabul edilmiş ve küretaj yapılmıştır. Ultrasonografi de sadece koryo-desidual dokusu saptanıp embriyo ve amnios mayii görülemedi ise ve serviks sonografik olarak $0.5 \mathrm{~cm}$ 'den daha fazla dilate ise inkomplet abort olarak kabul edilmiş ve küretaj uygulanmıştır. Uygulanan bütün küretaj materyelleri histopatolojik olarak incelenmiştir.

Elde edilen verilerin istatistiksel karşılaştırılmasında; niceliksel veriler ortalama +/-SS (standart sapma) olarak sunuldu. Ayrica Kruskall-Wallis testiyle, Man-Whitney U testi kullanıldı.

\section{Bulgular}

Çalışmaya alınan 45 hastanın \%72'si canlı doğum ile \%28‘i abort ile sonuçlanmıştır. Hastalara ait klinik ve demografik özellikler Tablo 1. de verilmiştir.

Tablo 1. Hastalara ait klinik ve demografik özellikler

\begin{tabular}{|c|c|c|c|c|c|}
\hline & & & & & \\
\hline & & $\mathrm{n}=32$ & $\%$ & $\mathrm{n}=13$ & 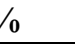 \\
\hline Kanamanın & 5-9. hafta & 20 & 62 & 6 & 46 \\
\hline Başladiğ1 & 10-14.hafta & 12 & 38 & 6 & 46 \\
\hline & 14-20. hafta & - & - & 1 & 8 \\
\hline Ilk kanama & 1 gun & 8 & 25 & 4 & 31 \\
\hline Atağının & 2 gun & 7 & 22 & 2 & 15 \\
\hline & 3 veya daha fazla & 17 & 53 & 7 & 54 \\
\hline
\end{tabular}


Özolcay, O., \& Șık, B. A. (2021). Birinci trimester düşük tehdidi olan hastalarda anembriyonik gebelik, intrauterin eksitus ve sağlıklı gebeliğin ayırıcı tanısında biyokimyasal parametrelerin yeri. Journal of Human Sciences, 18(3), 342-348. doi:10.14687/jhs.v18i3.6019

\begin{tabular}{|l|l|l|l|l|}
\hline & Ortalama & ss & En Küçük & En Büyük \\
\hline Yaş & 29.62 & 6.14 & 16 & 40 \\
\hline BMI & 23.37 & 11.32 & 18.50 & 28.96 \\
\hline Gravida & 2.48 & 1.35 & 1 & 7 \\
\hline Parite & 1.29 & 1.03 & 0 & 5.00 \\
\hline Abort & 0.22 & 0.55 & 0 & 3.00 \\
\hline Gebelik Haftas1 & 10.72 & 1.32 & 5.00 & 16.00 \\
\hline
\end{tabular}

Gebeliği canlı doğum ile sonuçlanan grup ile gebeliği spontan abortusla sonlanan grubun $\beta$-hCG, $\mathrm{P}_{4}, \mathrm{E}_{2}$ degerleri istatiksel olarak karşılaştırıldığında; canlı doğum ile sonuçlanan grupta anlamlı olarak yüksek bulunmuştur $(\mathrm{p}<0.01)$. (Tablo 2 .)

Tablo 2. Canlı Doğum ve Abortus gruplarının hormon parametreleri

\begin{tabular}{|c|c|c|c|c|c|c|c|}
\hline & \multicolumn{2}{|c|}{$\beta$-hCG (IU/ml) } & \multicolumn{2}{|c|}{ Progesteron $(\mathrm{ng} / \mathrm{ml})$} & \multicolumn{2}{|c|}{ Estradiol $(\mathrm{ng} / \mathrm{ml})$} \\
\hline & & \multicolumn{2}{|c|}{ Ortalama SS } & \multicolumn{2}{|c|}{ Ortalama $\quad$ ss } & \multicolumn{2}{|c|}{ Ortalama SS } \\
\hline $\begin{array}{l}\text { Canlı } \\
\text { Doğum }\end{array}$ & 32 & 30,95 & 16,81 & 42,78 & 13,15 & 12,50 & 3,84 \\
\hline Abortus & 13 & 12,82 & 7,00 & 12,66 & 4,028 & 7,48 & 1,92 \\
\hline $\mathrm{p}$ & & \multicolumn{2}{|c|}{0,0140} & \multicolumn{2}{|c|}{0,0113} & \multicolumn{2}{|c|}{0,005} \\
\hline
\end{tabular}

Abortus imminensli hastalarda $\beta$-hCG $\mathrm{E}_{2} \mathrm{P}_{4}$ düzeylerinin sensivite spesifite, negatif ve pozitif prediktif değerleri anlamlı çıkmışır (Tablo 3.)

Tablo 3. Abortus imminensli olgularda $\beta$-hCG, Progesteron, Estradiol degerlerinin sensitivite, spesifite, pozitif ve negatif prediktif değerleri

\begin{tabular}{|l|c|c|c|}
\hline & $\beta$-hCG & Progesteron & Estradiol \\
\hline Sensitivite & $\% 87.5$ & $\% 100$ & $\% 66.6$ \\
\hline Spesifite & $\% 83.7$ & $\% 95$ & $\% 83.3$ \\
\hline Pozitif prediktif deger & $\% 53$ & $\% 84.6$ & $\% 40$ \\
\hline $\begin{array}{l}\text { Negatif prediktif } \\
\text { deger }\end{array}$ & $\% 96$ & $\% 100$ & $\% 83$ \\
\hline
\end{tabular}

\section{Tartışma}

Bu çalışmaya dahil edilen abortus imminens tanısı alan hastaların demografik özelliklerinin gebeliğin prognozuna göre dağılımı incelendiğinde, jinekolojik ve sistemik hastalıklar, gravidite, daha önce küretaj geçirmiş olmasının prognozu etkilemediği görülmüştür. Sadece daha önce spontan abort geçiren hastalarda spontan düşük oranı daha yüksek olarak görülsede, aradaki bu farka habituel abortuslann etkisi ve etiyolojileri açısından yaklaşmak için hasta sayılarımız yetersizdir. Çalışmamızda vaginal kanamanın ilk başladiği hafta itibarıyla prognoz açısından anlamlı bir fark saptanmamıştır. Kanama süresi ile düşük insidansi arasında anlamlı bir ilişki bulunamamıştır. Oysa yapılan bir çalışmada üç gün ve daha fazla kanamanın devam ettiği vakalarda düşük riskinin belirgin olarak arttığı bildirilmiştir (Mantoni 1985).

Çalışmamızda $\beta$-hCG değerleri esas alındığında, abortus imminensli hastalarda serum $\beta$ hCG değerlerinin düşük olmasının sensitivitesi $\% 87.5$, spesifitesi $\% 83.7$, pozitif prediktif değeri $\%$ 53, negatif prediktif değeri \% 96 olarak saptanmıştır. Düssük seviyelerdeki $\beta$-hCG değerlerine sahip hastalar abortusla sonuçlanmıştır (Nygren et al. 1973). Bizim çalışmamızda ise gebeliği abortusla sonuçlanan hastaların \% 87.5'inde $\beta$-hCG değerleri düşük bulunmuştur. Progesteron seviyelerinin 
Özolcay, O., \& Șık, B. A. (2021). Birinci trimester düşük tehdidi olan hastalarda anembriyonik gebelik, intrauterin eksitus ve sağlıklı gebeliğin ayırıcı tanısında biyokimyasal parametrelerin yeri. Journal of Human Sciences, 18(3), 342-348. doi:10.14687/jhs.v18i3.6019

düşük olmasi intrauterin viable bir gebeliği ekarte ettirir fakat ektopik gebelik ile intrauterin nonviable bir gebeliği ayırt etmede yetersizdir.

Yapılan çeşitli araştırmalarda serum progesteron seviyelerinin 4-10 'uncu gebelik haftaları arasında ortalama $25 \mathrm{ng} / \mathrm{ml}$ olduğu ve 12. gebelik haftasından sonra giderek arttı̆̆ı saptanmıştır (Sproff et al. 1994). Bu çalışmada abortus imminens olgularında, serum progesteron seviyelerinin düşük olmasının sensitivitesi $\% 100$, spesifitesi $\% 95$, pozitif prediktif değeri $\% 84,6$, negatif prediktif değeri $\% 100$ olarak saptanmıştır. Hertz ve ark. abortus imminens olgularında progesteronun pozitif prediktif değerini \%100, negatif prediktif değerini \%80 olarak bulmuşlardır (Hertz 1984).

Witt ve ark. abortus imminens prognozunu belirlemede en iyi biyokimyasal parametrenin progesteron, ikinci sırada ise $\beta$-hCG olduğunu bildirmişlerdir (Witt et al. 1990). Bizim çalışmamızda da benzer olarak en iyi biyokimyasal parametre olarak progesteronu saptadik. $\beta$-hCG ikinci sırada yer alırken estradiol gebelik prognozunu belirlemede son sırada yer almiştır. Estradiol fetoplasental fonksiyonunun bozulmasının erken göstergelerinden biridir (Siiteri et al. 1966). Buna karşlık negatif prediktif değeri için Hertz ve ark. \%87, Eriksen ve ark. \%52 gibi düşük oranlar yayınlamışlardır (Hertz 1984; Eriksen \& Philipsen 1980). Çalışmamızda serum estradiol değerinin düşük olmasının abortus imminens için sensitivitesi $\% 66,6$, spesifitesi $\% 83,3$ pozitif prediktif değeri $\% 40$, negatif prediktif değeri $\% 83$ olarak bulunmuştur.

Anembriyonik ve intrauterin fetal/embriyonal eksitusu olan gebelikler düşükle sonuçlanmadan önce bir müddet uterusta kalma eğilimindedirler. Bu süre içinde kanama ve enfeksiyon gibi komplikasyonları engellemek ve abort tehdidi olan olguların hastanede kalış süresini kısaltmak için güvenilir tanı yöntemlerine ihtiyaç vardır. Son yıllarda hızlı teknolojik ilerlemeye paralel olarak geliştirilen transvajinal ultrason probları ile gerek pelvik organlara anatomik olarak transabdominal problardan daha yakın olması, gerekse sahip oldukları yüksek frekans ile kaliteli görüntü sağladıkları için özellikle erken gebelik tanı ve takibinde çalışmamızda çıkan sonuçlara benzer bir şekilde daha yararlı olduğu ortaya konulmuştur (Cullen et al. 1989; Penmell et al. 1991).

\section{Sonuç}

Düşük tehdidi, klinik olarak saptanmış gebeliklerde \% 25 gibi yüksek bir oranda görülen ve yaklaşık olarak \%50 oranında düşükle sonuçlanan bir erken gebelik komplikasyonudur. Hastada uzamış kan kaybı, enfeksiyon ve endişeli bekleyişe yol açmadan ilk başvuru anında embriyonun canlı olup, olmadığının kesin olarak saptamak klinisyenin ana amacıdır. Bu nedenle vajinal muayene sonrası yapılacak ilk iş hem vakit kaybını hem de doğru tanı oranını arttırmak için ilk olarak transvajinal ultrasonografik inceleme ve ardindan gerekirse hormonal parametreleri ( $\beta$-hCG, progesteron, estradiol) istemek olacaktır.

\section{Kaynaklar}

Ansan, K. (1989). Duşuk (Abortus) Dogum Bilgisi Cilt 11,3. Baski Istanbul, Qeltut Matbaacilik, s. 876

Canavagh, D. \& Comas, HR (1982). Spontaneous abortion. In Danforth DN (ed): Obstetrics and Gynecology. Philadelphia, Harper \& Row Pubs,p.378

Cullen, MT., Green, JJ., Reece, EA., Hobbins JC. (1989). Comparison of transvaginal and abdominal ultrasound in visualizing the first trimester conceptus. J Ultrasound Med.; 8: 5659.

Eriksen, PS., Philipsen, T (1980). Prognosis in threated abortion evaluated by hormone assay ultrasound scanning. Obstet Gynecol, 55:435.

Fantel, AG., Shepard, TH. (1981). Basic aspects of early (first trimester) abortion. Principles and Practice of Obstetrics and PerinataIogy, Vol 1. New York, John Wiley \& Sons, 1981, p.553

Filly, AR. (1988). The first trimester. In Cullen WP (ed): Ultrasonography in Obstetrics and Gynecology. Philadelphia, W.B. Saunders Company, p.19 
Özolcay, O., \& Șık, B. A. (2021). Birinci trimester düşük tehdidi olan hastalarda anembriyonik gebelik, intrauterin eksitus ve sağlıklı gebeliğin ayırıcı tanısında biyokimyasal parametrelerin yeri. Journal of Human Sciences, 18(3), 342-348. doi:10.14687/jhs.v18i3.6019

Glass, HR. (1989). Habituel Abortion. In Creasy and Resnic (ed) Matemal-Fetal Medicine: Principles and Practise. Second edition^^ Philadelphia, W.B. Saunders Company, 1989, p.437

Hertz, JB. (1984). Diagnostic procedures in threatened abortion. Obstet Gynecol, 66:223.

Homan, G., Brown, S., Moran, J., Homan, S., Kerin, J. (2000). Human chorionic gonadotropin as predictor of outcome in assited reproductive technology prognoces. Fertil Steril; 73 (2): 2704.

Hsu, MI., Kolm, P., Leete, J., Dong, KW., Muasher, S., Oehninger, S. (1998). Analysis of implantation in assisted reproduction through the use of serial human chorionic gonadotropin measurements. J Assist Reprod Genet, 18 (8): 496-503.

Mantoni, M. (1985). Ultrasound signs in thereated abortion and their prognostic significance. Obstet Gyncol, 65:471.

Nygren, KG., Johansson, EDB., Wide L. (1973). Evaluation of the prognosis of thereatened abortion from the peripheral plasma levels of the progesteron, estradiol and human chorionic gonadotropin. Am J. Obstet Gynecol, 7:116.

Penmell, RG., Nededlenon, L., Pajak, T., Baltarovich, D.(1991). Prospective comparison of vaginal and abdominal sonography in normal early pregnancy. Ultrasound Med. ; 10: 63-7.

Salem, HT., Ghaneimah S.A., Shaaban M.M., Chard,T. (1984). Prognostic value of biochemical tests in the assessment of fetal outcome in Threatened Abortion. Br J Obstet Gynaecol; 91(4):382-5.

Scott, RJ. (1986). Spontaneous Abortioa in Danforth ND (ed): Obstetrics \& Gynecology: Fifth edition. Philadelphia, JB. Lippincott Company, p.378

Siiteri, PK., Mac Donald, PC (1966). Placental estrogen biosynthesis during human pregnancy. J. Clin Endocrin Metab, 26:751.

Sproff, L., Glass, HR., Kase, NG. (1994). Clinical Gynecologic Endocrinology and infertility. Williams and Wilkins Fifth ed, 251-80.

Stabile, I., Campbell, S., Grudzinskas, J.G. (1989). Ultrasound and circulating placental protein measurements in complications of early pregnancy. Br. J. Obstet. Gynaecoi, 96, 1182-1191.

Westergaard, J.G., Teisner, B., Sinosich, M.J., Madsen, L.T., Grudzinskas, J.G. (1985). Does ultrasound examination render biochemical tests obsolete in the prediction of early pregnancy failure? Br. J. Obstet. Gynaecoi., 92, 77-83.

Witt, BR., Wolf, GC., Weinright, CJ. (1990). Relaxin Cal25, progesteron, estradiol, schwangerschaft protein and HCG as predictors of outcome in threatened and nonthreatened pregnancies Fertil Steril, 53:1029-36.

Yovkh, J.L. (1986). Placental hormone and protein measurements during conception cycles and early pregnancy. In Thomsen,K. and Ludwig.H. (eds), Proceedings of the Xl. World Congress K. of Gynecology and Obstetrics. Springer-Verlag,Berlin pp 854-857

Yovich, J. L., Willcox, D. L., Grudzinskas, J. G., Bolton.A.E. (1986). The prognostic value of hCG, PAPP-A, oestradiol-17 beta and progesterone in early human pregnancy. Aust.N.Z. J Obstet. Gynaecol. ,26,59-64.

\section{Extended English Summary}

In this study, it was aimed to establish criteria about the prognosis and life expectancy of pregnancy by using ultrasonographic imaging techniques and serum $\beta$-hCG, Estradiol, Progesterone levels as hormonal parameters to evaluate embryonic life potential in threatened miscarriage patients.

Our study consists of 45 pregnant patients who were admitted to Istanbul Taksim Training and Research Hospital Pregnant Outpatient Clinic due to vaginal bleeding during pregnancy and were diagnosed as threatened miscarriage. The study is designed in İstanbul Taksim Training and Research Hospital Obstetrics and Gynecology service, following the approval of the planning and ethics 
Özolcay, O., \& Şık, B. A. (2021). Birinci trimester düşük tehdidi olan hastalarda anembriyonik gebelik, intrauterin eksitus ve sağlıklı gebeliğin ayırıcı tanısında biyokimyasal parametrelerin yeri. Journal of Human Sciences, 18(3), 342-348. doi:10.14687/jhs.v18i3.6019

committee. Patients who did not have an additional gynecological pathology without any systemic disease and who were absolutely sure of their last menstrual date were included in the study groups. Pregnant women who were determined to have bleeding after vaginal examination due to a cervical polyp, erosion or eversion, multiple pregnancies, those diagnosed with ectopic and chemical pregnancy were excluded from the study. The study group consisted of pregnant women diagnosed as abortus imminens of 20 weeks or less gestational week compared to the last menstrual date. $10 \mathrm{cc}$ blood was taken from the antecubital veins of all patients included in the study and analyzed. Estradiol $\left(\mathrm{E}_{2}\right)$, Progestrone $\left(\mathrm{P}_{4}\right), \beta-\mathrm{hCG}$ measurements were made at the same time from all blood samples collected. Estradiol and progesterone measurements were made with Coast A-Count Estradiol and Progesterone kits working with solid phase radioimmunoassay technique. $\beta$-hCG was measured with IRMA-mat $\beta$-hCG, kits based on the sandwich radioimmunoassay technique. Initially detailed systemic, gynecological and obstetric anamnesis of each patient were taken and then transvaginal sonographic pelvic examinations were performed by using Shimadzu brand SDU-350A model real time linear convex probe ultrasonography device and EUP-V12 model $5 \mathrm{mHz}$ vaginal probe. The main purpose in ultrasonographic examination was to detect fetal heart movements. In early pregnancies where the embryo was not visible in transvaginal ultrasound examination, the mean gestational sac diameter (OGKÇ) was found by measuring the size of the gestational sac by 3 dimension and averaging it. Pregnancies in which OGKÇ is over $25 \mathrm{~mm}$, in which fetal heart movements $(\mathrm{FKH})$ could not be detected, was accepted as an anembryonic pregnancy and therapeutic curettage was applied. In addition to this examination, $\beta-h C G$, progesterone, estradiol level blood samples were taken in all groups. If the fetus is visible, CRL and BPD were measured and fetal heartbeat movements were detected. Embryos larger than $10 \mathrm{~mm}$ without fetal cardiac activity were accepted as missed abortion and curettage was performed. In ultrasonography, if only choriodecidual tissue was detected, the embryo and amniotic fluid could not be seen, cervix was sonographically dilated more than $0.5 \mathrm{~cm}$, is accepted an incomplete abortion. All curettage materials send to histopathological examination. In the statistical comparison of the data obtained; quantitative data are presented as mean +/- SD (standard deviation). In addition, Kruskall-Wallis test and ManWhitney U test were used.

Of the 45 patients included in the study, $72 \%$ resulted in live birth and $28 \%$ resulted in abortion. The group whose pregnancy resulted with live birth and the group whose pregnancy terminated with spontaneous abortion were statistically compared according to their hormonal parameters; it was found to be significantly higher in the group that resulted in live birth $(p<0.01)$. Sensitivity, specificity, negative and positive predictive values of $\beta-h C G, E 2$, P4 levels were found to be significant in patients with threatened miscarriage.

Threatened miscarriage treatments have allowed close examination of women likely to conceive and attention has focused on the conception cycle and events occurring during early pregnancy, with accurate monitoring of the timing of ovulation and conception. There was adverse influence of maternal age and abortion history on outcomes in pregnancies with threatened miscarriages Most studies have demonstrated the potential for hormonal monitoring in the prediction of pregnancy outcome. Also bleeding amount and characteristics are related with poor fetal outcome. The threat of miscarriage is an early pregnancy complication that occurs in clinically established pregnancies as high as $25 \%$ and results in approximately $50 \%$ miscarriage. It is the clinician's main goal to determine whether the embryo is alive or not at the time of initial examination without causing prolonged blood loss, infection and anxious wait. For this reason, the first thing to do after the vaginal examination would be to request transvaginal ultrasonographic examination first and then, if necessary, hormonal parameters ( $\beta$-hCG, progesterone, estradiol) if necessary. 